\title{
Self-rated health and hospital services use in the Spanish National Health System: a longitudinal study
}

Nayara Tamayo-Fonseca ${ }^{1}$, Andreu Nolasco ${ }^{1 *}$, Jose A. Quesada', Pamela Pereyra-Zamora', Inmaculada Melchor ${ }^{1,2}$, Joaquin Moncho', Julia Calabuig ${ }^{3}$ and Carmen Barona ${ }^{4}$

\begin{abstract}
Background: Self-rated health is a subjective measure that has been related to indicators such as mortality, morbidity, functional capacity, and the use of health services. In Spain, there are few longitudinal studies associating self-rated health with hospital services use. The purpose of this study is to analyze the association between self-rated health and socioeconomic, demographic, and health variables, and the use of hospital services among the general population in the Region of Valencia, Spain.

Methods: Longitudinal study of 5,275 adults who were included in the 2005 Region of Valencia Health Survey and linked to the Minimum Hospital Data Set between 2006 and 2009. Logistic regression models were used to calculate the odds ratios between use of hospital services and self-rated health, sex, age, educational level, employment status, income, country of birth, chronic conditions, disability and previous use of hospital services.
\end{abstract}

Results: By the end of a 4-year follow-up period, 1,184 participants (22.4 \%) had used hospital services. Use of hospital services was associated with poor self-rated health among both men and women. In men, it was also associated with unemployment, low income, and the presence of a chronic disease. In women, it was associated with low educational level, the presence of a disability, previous hospital services use, and the presence of chronic disease. Interactions were detected between self-rated health and chronic disease in men and between self-rated health and educational level in women.

Conclusions: Self-rated health acts as a predictor of hospital services use. Various health and socioeconomic variables provide additional predictive capacity. Interactions were detected between self-rated health and other variables that may reflect different complex predictive models, by gender.

Keywords: Self-rated health, Hospitalization, Health services use, Health indicators, Longitudinal study

\section{Background}

Self-rated health (SRH) is a simple measure that has been shown to be a good indicator since it provides a global overview of a population's health status and has been related at the individual level to indicators such as mortality, morbidity, functional capacity, and use of health services, among others [1-4]. This subjective

\footnotetext{
* Correspondence: nolasco@ua.es

'Department of Community Nursing, Research Unit for the Analysis of Mortality and Health Statistics, Preventive Medicine, Public Health and History of Science. University of Alicante. Campus de San Vicente del Raspeig s/n, Apartado 99, 03080 Alicante, Spain

Full list of author information is available at the end of the article
}

measure has been related to people's willingness to make an effort to maintain a good state of health [5].

As several studies have indicated, one of the advantages of assessing self-rated health is that this measure incorporates individual perspectives on health and disease. Nevertheless, there is widespread debate about its use in public health policies because it has been suggested that selfrated health may provide misleading information or could underestimate social inequalities in health [6]. However, recent research findings reported in several studies have indicated that the predictive validity of SRH has increased over time [7]. 
Previous studies, mostly conducted in the United States and Finland, have demonstrated that self-rated health is a predictor of health services use [1, 3, 8-12], as well as a good indicator of the health and medical care needs and services in a community [13]. It has been suggested that monitoring SRH could constitute a practical tool for health managers, researchers and policymakers when assessing possible changes in health service needs [9], as well as for predicting hospital admission [12] and identifying older adults at increased risk for admission to nursing homes [8]. In addition, this indicator has been used to identify groups at risk so as to analyze hospital costs $[10,12]$.

It has been reported that health status is a major determinant of the use of hospital services (HS) in universal health care systems [14]. Thus, there is a need for indicators that make it possible to monitor changes in a population's health status, the system's responses and consequently, health outcomes. Objective measures such as annual number of visits to the doctor, average hospital stay, or number of beds have been widely used in studies on health services use. Self-rated health is a short measure, with the advantage of being less expensive and less burdensome to collect, and can conceivably be collected with relative ease [3].

As a result of European Union recommendations for improving information systems, those responsible for making decisions on health currently use various harmonized resources as their main sources of information, such as health surveys and medical and administrative records, which together provide an accessible and updated overview of changes in health status and available resources.

Some studies have examined the association between SRH and HS use. However, this relationship has not yet been clearly established in Spain, partly because of the difficulties involved in associating this type of indicator with different sources of information, and partly because SRH has only been studied in elderly populations [15-17]. A previous study conducted in the Region of Valencia (RV) linked the 2005 Region of Valencia Health Survey (RVHS2005) cohort to the RV mortality register; after 4 years of monitoring, it was found that SRH acted as a predictor of mortality in the general population for both men and women, and also mediated between socioeconomic, demographic, and health conditions, and mortality [18]. At national level, however, few studies in Spain $[16,19]$ have attempted to link a cohort to information derived from the Minimum Basic Hospital Data Set (MBDS) so as to establish profiles on the use of HS and hospitalization outcomes.

Given the lack of longitudinal studies in Spain associating SRH with the use of HS in the general population, the aim of the present study was to describe and analyze the association and predictive capacity of SRH, socioeconomic, demographic, and health status variables as regards HS use in people over 20 years of age, based on monitoring the RVHS2005 adult cohort linked to the MBDS of public hospitals in the Region of Valencia.

\section{Methods}

\section{Study design and sample}

This is a longitudinal follow-up study of a cohort of adults who comprised the RVHS2005 sample [20]. The initial sample consisted of 5,481 participants, all of whom were aged over 20 years and were noninstitutional residents of the RV, a Mediterranean region in eastern Spain $(5,004,844$ inhabitants in 2005). The study sample was representative of the RV and was obtained by means of a complex sample design whereby all participants were assigned a weight according to their representativeness, and these weights were included in the RVHS2005 databases supplied by the Health Plan Office at the Health Department of the Regional Government of Valencia.

\section{Measures}

The study's response variable was use of HS, dichotomized into "use"/"non-use". Use was defined as any admission to the hospital for acute care or major outpatient surgery (including admissions with a stay less than $24 \mathrm{~h}$ ) and chronic or long-stay hospitalization.

At the time of this study, the overall population in Spain had health insurance and medical coverage, and a physician decision was needed for hospitalization, which was scheduled or carried out through the emergency service. Hospitalization related to childbirth and caesarean section (180 cases, $6.8 \%$ of admissions) was excluded. Results for the response variable were obtained by means of linking the RVHS2005 database to the Hospital Discharge Register (the MBDS) for 32 hospitals in the RV, over a 4-year follow-up period from 1 January 2006 to 31 December 2009. It is mandatory for all public hospitals in Spain to update the MBDS, which aggregates all information from hospitals in a standardized, coded, electronic format that is compatible with other information systems. The register is also used by various researchers and planners as a source of data for analysis of health status and outcomes, as well as for health planning and resource assessment [19, 21-24].

The main explanatory variable was $\mathrm{SRH}$, based on the following RVHS2005 question: "Right now, how would you describe your health?" In accordance with common recoding practice, the possible answers (Very good/Good/Fair/ Poor/Very poor/Don't know or no answer) were aggregated into two categories: Good (good or very good) and Poor (fair, poor or very poor). To control for the possible explanatory or confounding effect or interaction of the socioeconomic context and morbidity, the following explanatory variables with their corresponding categories were included in the analyses: sex (female, male), age (21-44, $45-64,65-84, \geq 85$ years), educational level (primary or 
lower, higher than primary), employment status (working, not working), self-rated income level (low, medium-high), country of birth (Spain, abroad), presence of chronic disease (yes, no) or disability (yes, no), and use of HS in the year prior to the survey (yes, no). Categorization of the variables was made according to a previous study on SRH and mortality using this cohort [18]. The question addressing self-rated income level was "How would you describe your level of income?" Possible responses were: High/Mediumhigh/Medium/Medium-low/Low/Don't know, or no answer provided. This variable was recategorized into Low (low or medium-low) and Medium-high (high, mediumhigh or medium).

\section{Data analysis}

Frequencies and percentages of HS use were calculated for each level of the explanatory variables, by sex and for the total. To analyze the association between use of HS and the explanatory variables, logistic regression models were adjusted with the response variable (use of HS; yes/ no), using the likelihood ratio to test likelihood increases between models, and the Wald statistic to test significance for the variables included in each model. The odds ratio $(\mathrm{OR})$ was calculated as a measure of the association between use of HS and the explanatory variable categories, together with the corresponding $95 \%$ confidence intervals $(95 \% \mathrm{CI})$. ORs were obtained for HS use with each explanatory variable in a simple analysis, adjusted for age, and finally adjusting for all variables, including and removing SRH to determine its effect on the model. An analysis was conducted of the possible interaction between SRH as the main explanatory variable and the other explanatory variables. All analyses were performed separately by sex and considering the complex sample design. The weights of the sample participants were introduced in the weights option of the statistical package. Statistical analysis was performed using the $R$ 2.12.2 software package ( $\mathrm{R}$ Foundation for Statistical Computing, Vienna, Austria).

\section{Ethical considerations}

Owing to the characteristics of this prospective observational study based on administrative data, this research posed no ethical issues because the researchers only had access to data rendered anonymous via a complex process of linking databases, which were only handled by authorized staff from the responsible information systems departments of the Region of Valencia Department of Health.

\section{Results}

A total of 206 participants were excluded from the follow-up, either because their records could not be linked with complete certainty (178 cases) or because they had died in 2005 (28 cases), leaving a total of 5,275 participants for follow-up and analysis.

During the period monitored, 1,184 (22.4\%) individuals used HS, of whom 585 were men (49.4\%) and 599 women $(50.6 \%)$. No significant difference by sex was observed in the percentage of HS use, which was $22.6 \%$ for men and $22.3 \%$ for women. Table 1 shows the number and percentage of individuals who used HS, separated by sex and for the total, for each level of the explanatory variables. For men, women, and the total alike, greater use was made of HS by participants who reported poor self-rated health, chronic disease, or disability, those who had a primary education or lower, low income, and who were older, unemployed, born in Spain, and who had used HS in the previous year.

A simple analysis revealed that all variables were significant predictors of HS use in the follow-up period for both men and women, except in the case of the country of birth variable among women (Table 2 and Table 3). When adjusted for age, all variables except disability were significant predictors for men, whereas significant predictors for women were poor self-rated health, chronic disease, disability, and previous use of HS.

In the model adjusted for all variables except SRH, those participants most at risk of hospitalization were unemployed men with low income and chronic disease. When SRH was included in the model, a significant interaction was seen between SRH and the presence of chronic disease, significantly increasing the log likelihood ratio from 206.6, with 6 degrees of freedom to 219.9 , with 8 degrees of freedom $(p<0.001)$. Thus, in the group of people with chronic disease, those who reported poor health were significantly more likely to be hospitalized than those reporting good health $(\mathrm{OR}=1.7$, $95 \% \mathrm{CI}=[1.3-2.5])$. However, the result was not significant in the group without chronic disease (OR $=0.7,95 \%$ $\mathrm{CI}=[0.3-1.5])$.

When adjusted for all variables except SRH, having chronic disease, disability or previous use of HS significantly increased the likelihood of using HS for women. When SRH was included in the model, these three variables remained significant, and a significant interaction between SRH and educational level was also observed, significantly increasing the log likelihood ratio from 177.7, with 7 degrees of freedom to 198.3, with 9 degrees of freedom $(p<0.001)$. Thus, those who reported poor health were more likely to be hospitalized, but the association was significantly stronger in the group with higher educational level $(\mathrm{OR}=2.6,95 \% \mathrm{CI}=[1.7-4.0])$ than in the group with lower educational level $(\mathrm{OR}=1.3,95 \% \mathrm{CI}=[1.0-1.5])$.

\section{Discussion}

This study revealed that in Spain, SRH is a predictor of HS use. After 4 years of following the RVHS2005 cohort, 
Table 1 Frequency and percentage distributions of hospital service use by sex, according to explanatory variable categories

\begin{tabular}{|c|c|c|c|c|c|c|c|}
\hline \multirow[t]{3}{*}{ Explanatory variables (missing data ${ }^{a}$ ) } & & \multicolumn{6}{|c|}{ Use of hospital services } \\
\hline & & \multicolumn{2}{|l|}{ Men } & \multicolumn{2}{|c|}{ Women } & \multicolumn{2}{|l|}{ Total } \\
\hline & & $n$ & $\%$ & $n$ & $\%$ & $n$ & $\%$ \\
\hline Total sample & & 585 & 22.6 & 599 & 22.3 & 1184 & 22.4 \\
\hline \multirow[t]{2}{*}{ Self-rated health (18) } & Good & 372 & 18.4 & 317 & 17.0 & 689 & 17.7 \\
\hline & Poor & 211 & 37.5 & 279 & 34.7 & 490 & 35.9 \\
\hline \multirow[t]{4}{*}{ Age (9) } & $21-44$ & 191 & 14.0 & 200 & 15.4 & 391 & 14.7 \\
\hline & $45-64$ & 175 & 22.5 & 161 & 20.7 & 336 & 21.6 \\
\hline & $65-84$ & 207 & 48.8 & 203 & 38.2 & 410 & 43.0 \\
\hline & $85+$ & 12 & 46.2 & 33 & 46.5 & 45 & 46.4 \\
\hline \multirow[t]{2}{*}{ Employment status (168) } & Working & 274 & 15.6 & 173 & 16.3 & 447 & 15.8 \\
\hline & Not working & 286 & 37.9 & 386 & 25.3 & 672 & 29.5 \\
\hline \multirow[t]{2}{*}{ Educational level (75) } & Primary or lower & 419 & 26.6 & 444 & 26.0 & 863 & 26.3 \\
\hline & Higher than primary & 158 & 16.1 & 149 & 15.8 & 307 & 16.0 \\
\hline \multirow[t]{2}{*}{ Income level (505) } & Medium-high & 324 & 20.1 & 307 & 19.7 & 631 & 19.9 \\
\hline & Low & 216 & 29.2 & 235 & 27.4 & 451 & 28.2 \\
\hline \multirow[t]{2}{*}{ Country of birth (284) } & Spain & 523 & 23.7 & 510 & 22.4 & 1033 & 23.0 \\
\hline & Other & 36 & 14.5 & 43 & 17.1 & 79 & 15.8 \\
\hline \multirow[t]{2}{*}{ Chronic disease (4) } & Yes & 391 & 28.6 & 480 & 26.8 & 871 & 27.6 \\
\hline & No & 195 & 15.8 & 118 & 13.3 & 313 & 14.8 \\
\hline \multirow[t]{2}{*}{ Disability (7) } & Yes & 86 & 38.7 & 111 & 41.9 & 197 & 40.5 \\
\hline & No & 498 & 21.0 & 487 & 20.2 & 985 & 20.6 \\
\hline \multirow[t]{2}{*}{ Previous use of hospital services (11) } & Yes & 303 & 26.7 & 366 & 25.9 & 669 & 26.3 \\
\hline & No & 282 & 19.3 & 232 & 18.3 & 514 & 18.9 \\
\hline
\end{tabular}

aTotal number of people who responded "Don't know" or did not provide an answer

participants who reported poor SRH had a higher risk of using HS than people who reported good health. This predictive role was significant even after adjusting for age, health status, and sociodemographic characteristics.

These findings are consistent with those reported in studies conducted in other countries, in which SRH has been described as one of the determinants of hospitalization and the use of other health services. For example, De Salvo et al. [3] found that poor SRH was a predictor of mortality, hospitalization, and high use of outpatient services. A study by Weinberger et al. [8] showed that poor SRH was a risk factor for hospitalization and residence in nursing homes or homes for the elderly. McGee et al. [11] found that people with poor SRH presented higher values for two measures of HS use, namely, mean number of days in bed and average number of visits to the doctor in the previous 12 months; these results are similar to findings reported in a study by Miilumpalo et al. [9] conducted in Finland.

In this study, we found that over the 4 years of followup, 22.4 \% of respondents used HS. Using a follow-up period of the same length but in a cohort aged over 64 , Suárez García [17] obtained a higher hospitalization percentage $(29.6 \%)$ for the overall follow-up, which could be attributed to the older age of the cohort studied. In our study, the mean annual percentage obtained for hospitalization was $5.6 \%$. This figure is lower than that reported in other cross-sectional studies $[25,26]$, in which the annual percentage obtained for hospital admissions in Spain was $9.3 \%$, a little lower than the mean of $10.9 \%$ reported for the European Union [27]; however, these studies were based on self-reported responses, which may explain the differences. Differences could be also explained by the exclusion of childbirths and caesarean sections in our study.

According to results of the simple analyses, the most common profile of patients who had used HS was that of participants who reported poor self-rated health, were older, born in Spain, unemployed, had primary education or below, a low income, chronic disease, disability, or had used health services in the previous year. These results are consistent with findings obtained in other studies conducted in Spain, although there are some differences.

With regard to age, a sharp increase in hospital admissions in Spain in recent years has been reported, which is partially attributable to the aging population [14]. 
Table 2 Association between use of hospital services and studied variables, among men

\begin{tabular}{|c|c|c|c|c|c|}
\hline Men & & $\begin{array}{l}\text { Simple } \\
\text { analysis }^{\mathrm{a}}\end{array}$ & $\begin{array}{l}\text { Adjusted } \\
\text { by age }^{\mathrm{a}}\end{array}$ & $\begin{array}{l}\text { Analysis adjusting for all variables, } \\
\text { not including } S R H^{b} L^{c}=206.6 ; d f=6\end{array}$ & $\begin{array}{l}\text { Analysis adjusting for all variables, } \\
\text { including } S R H^{b} L^{c}=219.9 ; d f=8\end{array}$ \\
\hline \multirow[t]{4}{*}{ Age } & $21-44$ & 1 & - & 1 & 1 \\
\hline & $45-64$ & $1.8(1.4-2.2)$ & & $\mathbf{1 . 5}(1.2-1.9)$ & $1.4(1.1-1.8)$ \\
\hline & $65-84$ & $5.9(4.6-7.6)$ & & $3.5(2.4-5.1)$ & $3.4(2.3-5.0)$ \\
\hline & $85+$ & $5.3(2.4-11.8)$ & & $3.1(1.3-7.4)$ & $3.0(1.2-7.3)$ \\
\hline \multirow[t]{2}{*}{ Self-rated health } & Good & 1 & 1 & & 1 \\
\hline & Poor & $2.7(2.2-3.3)$ & $1.8(1.4-2.2)$ & & $0.7(0.3-1.5)$ \\
\hline \multirow[t]{2}{*}{ Chronic disease } & No & 1 & 1 & 1 & 1 \\
\hline & Yes & $2.1(1.7-2.6)$ & $1.3(1.1-1.6)$ & $1.3(1.1-1.7)$ & $1.1(0.8-1.4)$ \\
\hline \multirow[t]{2}{*}{ Disability } & No & 1 & 1 & NS & NS \\
\hline & Yes & $2.4(1.8-3.2)$ & $1.4(0.9-1.9)$ & & \\
\hline \multirow[t]{2}{*}{ Employment status } & Working & 1 & 1 & 1 & 1 \\
\hline & Not working & $3.3(2.7-4.1)$ & $1.5(1.1-2.0)$ & $1.5(1.1 .-2.0)$ & $1.4(1.0-1.9)$ \\
\hline \multirow[t]{2}{*}{ Educational Level } & Higher than primary & 1 & 1 & NS & NS \\
\hline & Primary or lower & $1.9(1.5-2.3)$ & $1.3(1.0-1.6)$ & & \\
\hline \multirow[t]{2}{*}{ Income level } & Medium-high & 1 & 1 & 1 & 1 \\
\hline & Low & $1.6(1.3-2.0)$ & $1.3(1.1-1.6)$ & $1.3(1.0-1.6)$ & $1.3(1.0-1.6)$ \\
\hline \multirow{2}{*}{$\begin{array}{l}\text { Previous use of } \\
\text { hospital services }\end{array}$} & Yes & 1 & 1 & NS & NS \\
\hline & No & $\mathbf{1 . 5}(1.3-1.8)$ & $1.2(1.0-1.5)$ & & \\
\hline \multirow[t]{2}{*}{ Country of birth } & Other & 1 & 1 & NS & NS \\
\hline & Spain & $1.9(1.3-2.7)$ & $1.5(1.0-2.2)$ & & \\
\hline \multirow[t]{2}{*}{ Chronic disease NO } & Good health & - & - & & 1 \\
\hline & Poor health & & & & $0.7(0.3-1.5)$ \\
\hline \multirow[t]{2}{*}{ Chronic disease YES } & Good health & & & & 1 \\
\hline & Poor health & & & & $1.7(1.3-2.5)$ \\
\hline
\end{tabular}

${ }^{\mathrm{a}}$ Odds ratios (95\% confidence interval). Statistically significant odds ratios in bold, $P<0.05$

${ }^{b}$ Final model included only variables with significant adjusted effects

${ }^{c} L$ Likelihood ratio test for assessing significance of likelihood increase for the model vs. the model with only a constant

Abbreviations: SRH self-rated health; df, degrees of freedom, NS not significant

However, another study has suggested that use of hospital resources may not be related to age so much as to the type of hospital admission [28]. In that study as well as in the majority of studies [29], no significant differences were found by sex. However, some studies in Spain have reported sex inequalities in the provision of hospital care that favor men [14-16, 30,31], which highlights important implications for healthcare organizations. It is reasonable to assume that had diagnosis codes related to childbirth been included in this study, we would likely have found a slight predominance of HS use by women; such a finding would coincide with the results of the hospital register [32] as well as with recent data from cross-sectional studies, the Spanish Health Survey [26], and the Region of Valencia Health Survey [25].

Our results for country of birth agree with those of the last Spanish Health Survey (2011-12), indicating that Spanish-born people make most use of HS. However, some studies differ in this respect, perhaps because of the heterogeneity of the groups analyzed. These studies have reported a greater tendency among immigrants to use hospital emergency services as a substitute for other healthcare services [33, 34], although there is evidence that utilization rates among Spanish people of outpatient, emergency, and hospitalization services exceed the corresponding rates among immigrants $[35,36]$. Our results regarding lower use by immigrants could be explained by the exclusion of diagnoses related to childbirths, which are more common among immigrant women [35]; possible difficulties for immigrants to access the health system [37]; and the "healthy migrant effect" that has been described in Spain [38].

With regard to education, we found that a low educational level was associated with increased use of HS. This result coincides with the trend observed in health surveys in Spain and the Region of Valencia, in which people who could not read or had not completed their primary education presented higher utilization rates than 
Table 3 Association between use of hospital services and studied variables, among women

\begin{tabular}{|c|c|c|c|c|c|}
\hline Women & & $\begin{array}{l}\text { Simple } \\
\text { analysis }^{\mathrm{a}}\end{array}$ & $\begin{array}{l}\text { Adjusted by } \\
\text { age }^{a}\end{array}$ & $\begin{array}{l}\text { Analysis adjusting for all variables, } \\
\text { not including } S R H^{a, b} L^{c}=177.7 ; d f=7\end{array}$ & $\begin{array}{l}\text { Analysis adjusting for all variables, } \\
\text { including } S R H^{a, b} L^{c}=198.3 ; d f=9\end{array}$ \\
\hline \multirow[t]{4}{*}{ Age } & $21-44$ & 1 & - & 1 & 1 \\
\hline & $45-64$ & $1.4(1.2-1.8)$ & & $1.2(0.9-1.5)$ & $1.1(0.8-1.4)$ \\
\hline & $65-84$ & $3.4(2.7-4.2)$ & & $2.5(1.9-3.2)$ & $2.2(1.7-2.9)$ \\
\hline & $85+$ & $4.8(3.0-7.8)$ & & $3.4(2.0-5.7)$ & $2.7(1.6-4.6)$ \\
\hline \multirow[t]{2}{*}{ Self-rated health } & Good & 1 & 1 & - & 1 \\
\hline & Poor & $2.6(2.2-3.1)$ & $1.9(1.5-2.3)$ & & $2.6(1.7-4.0)$ \\
\hline \multirow[t]{2}{*}{ Chronic disease } & No & 1 & 1 & 1 & 1 \\
\hline & Yes & $2.4(1.9-3.0)$ & $1.8(1.4-2.2)$ & $1.6(1.3-2.0)$ & $1.4(1.1-1.8)$ \\
\hline \multirow[t]{2}{*}{ Disability } & No & 1 & 1 & 1 & 1 \\
\hline & Yes & $2.9(2.2-3.7)$ & $1.8(1.3-2.4)$ & $1.6(1.2-2.1)$ & $1.5(1.1-2.0)$ \\
\hline \multirow[t]{2}{*}{ Employment status } & Working & 1 & 1 & NS & NS \\
\hline & Not working & $1.7(1.4-2.1)$ & $1.0(0.8-1.3)$ & & \\
\hline \multirow[t]{2}{*}{ Educational Level } & Higher than primary & 1 & 1 & $1.2(0.9-1.5)$ & 1 \\
\hline & Primary or lower & $1.9(1.5-2.3)$ & $1.2(0.9-1.5)$ & & $1.4(1.0-1.8)$ \\
\hline \multirow[t]{2}{*}{ Income level } & Medium-high & 1 & 1 & NS & NS \\
\hline & Low & $1.5(1.3-1.9)$ & $1.2(0.9-1.4)$ & & \\
\hline \multirow{2}{*}{$\begin{array}{l}\text { Previous use of } \\
\text { hospital services }\end{array}$} & Yes & 1 & 1 & 1 & 1 \\
\hline & No & $1.6(1.3-1.9)$ & $1.5(1.2-1.8)$ & $1.3(1.1-1.6)$ & $1.3(1.1-1.6)$ \\
\hline \multirow[t]{2}{*}{ Country of birth } & Other & 1 & 1 & NS & NS \\
\hline & Spain & $1.4(1.0-2.0)$ & $1.2(0.8-1.6)$ & & \\
\hline \multirow{2}{*}{$\begin{array}{l}\text { Educational level: } \\
\text { Higher than primary }\end{array}$} & Good health & - & - & - & 1 \\
\hline & Poor health & & & & $2.6(1.7-4.0)$ \\
\hline \multirow{2}{*}{$\begin{array}{l}\text { Educational level: } \\
\text { Primary or lower }\end{array}$} & Good health & & & & 1 \\
\hline & Poor health & & & & $1.3(1.0-1.5)$ \\
\hline
\end{tabular}

${ }^{\mathrm{a}}$ Odds ratios (95\% confidence interval). Statistically significant odds ratios in bold, $P<0.05$

b Final model included only variables with significant adjusted effects

${ }^{c} L$ Likelihood ratio test for assessing significance of likelihood increase for the model vs. the model with only a constant

Abbreviations: SRH self-rated health, $d f$ degrees of freedom, NS not significant

those with tertiary or vocational education, although with slight variations by age and sex $[25,26]$. However, our result differs from that of another study in which the opposite association was observed, namely, that people with a higher educational level tended to consume more health services, owing in part to the attitude of doctors regarding the degree of patient information [39].

A multivariate analysis adjusting for all the variables studied revealed the importance for men of socioeconomic variables (employment status and income level) and the interaction of SRH with chronic disease. In contrast, the most important variables for women were those related to health status (chronic disease and disability) and previous use of HS, as well as the interaction of SRH with educational level.

Although this study only analyzed data pertaining to the public health system and thus excluded private hospitals, which provide $\mathrm{HS}$ to a higher percentage of high income individuals [40], the adjusted results for men nevertheless indicate that independently of $\mathrm{SRH}$, income level was a predictor of HS use. Other studies have reported finding no significant inequalities by socioeconomic status for hospitalization in Spain [14, 40-42]. In agreement with findings reported by Regidor et al. [43] and the Region of Valencia [25], our results show that people with lower incomes presented higher rates of hospitalization.

The results of both simple and multivariate analyses of employment status indicate that independently of SRH, unemployed men were at the highest risk of hospitalization. The lower rates of HS use among employed people might in part be owing to the higher time/opportunity costs faced by working individuals, which are reflected in their greater reluctance to initiate or prolong a stay in hospital [39].

For both sexes, the presence of chronic disease increased the risk of HS use. This result agrees with those of previous 
studies because chronic disease, degree of severity, and comorbidity have all been described as important risk factors for hospitalization [16, 17, 29, 30, 44].

For men, the interaction between SRH and the presence of chronic disease led to increased risk of hospitalization when poor SRH was reported, but only among those who had a chronic disease. This result might indicate that men with chronic disease who reported poor SRH reinforced their negative assessment owing to poor health status, which probably led them to be hospitalized. This hypothesis might correspond to the relationship between SRH and mortality described by other authors, whereby men but not women who rated their health as poor were found to be at higher risk of dying, suggesting that men with chronic disease had more life-threatening conditions whereas women had more disabling conditions, and consequently made less use of HS and greater use of primary healthcare $[18,30,45]$.

The results for women show that independently of SRH, previous use of HS was a predictor of HS use, in agreement with other studies in which this variable has been described as a major predictor of subsequent hospitalization and has also been associated with increased mortality and stay in nursing homes [15]. Disability and chronic disease were also predictors of HS use, again independently of SRH, and these have also been described as predictors of mortality $[18,45]$.

Educational level presented a complex behavior among women, interacting with SRH in such a way that risk of HS use was higher among women reporting poor SRH; however, the association was stronger in those with higher educational level than in those with lower educational level. This latter finding may be consistent with the effect described by Schnittker and Bacak [7], whereby the predictive validity of SRH increases as educational level rises. This finding may also be in line with other studies that have analyzed the role of education in the search for and consumption of health services $[39,41]$ and in which several hypotheses have been proposed, for instance that the use of health services depends on the degree to which individuals value their own health, and thus efficient production of health increases as educational level rises. Another hypothesis proposes that people with a higher educational level tend to use health services more often and in a more timely manner, owing in part to a greater awareness about the importance of health and different attitudes towards the health system, leading to a broader demand for healthcare and better knowledge of how the health system functions.

The end of the study period coincided with the beginning of the severe economic downturn that has been affecting Europe and Spain since 2008, and our results correspond to a period of public and universal healthcare in Spain. Although Spain's universal healthcare system should ensure equitable access, several studies have explored the existence of inequalities in use of the public healthcare system [39-41, 46], which may have increased in recent years as a consequence of changes in the economic context and health and social reforms [47, 48].

These inequalities may partially explain some of the results obtained in our study. Changes to the healthcare model such as restrictions on certain health benefits, limiting the basic portfolio of services, exclusion or limitation of various groups (for instance, undocumented immigrants who were previously entitled to receive certain medical treatments), or implementation of co-payment, should be avoided since they could widen disparities in primary and hospital healthcare service use, as has been reported in other European countries with policies aimed at reducing public spending on health [49].

The expected changes in health outcomes as a consequence of changes resulting from the economic crisis suggest the need to monitor indicators such as SRH, together with socioeconomic and health indicators, such as those used in this study.

\section{Strengths and limitations}

One of the strengths of this study was the size of the study sample and its representativeness relative to the general population. Moreover, the study included the general population aged over 20 years old, encompassing a wide age range but adjusting for age in the models. Another strength of the study was its use of data from the RVHS2005, which was designed and validated for obtaining population data on the variables studied and had a very high response rate.

Limitations included losses during follow-up, respondents who may have used HS in other locations or people who had used private hospitals, since it has been reported that people with a more favorable socioeconomic status are more likely to use additional private insurance [40, 41, 46]. In addition, the exclusion of participants who died in 2005 may have reduced the impact of the hospitalization factors studied; these participants might have had worse health indicators [16] but could not make use of HS because they had died.

Regarding the quality of data from the MBDS, this information system is now widely used in clinical and epidemiological research, and although initially some studies had reported various limitations concerning the quality of clinical information $[22,50]$ others have since established its reliability and validity as a source for observational study [23, 24].

One of the most widely used indicators of HS use is volume of use, which includes number of admissions and length of stay. Our study is based only on the use or non-use of HS, without considering high-frequency 
users. Length of stay and total number of admissions might present different results.

\section{Conclusions}

This study has shown that SRH is a predictor of hospital service use after 4 years of follow-up among the general population in Spain, a subject which has received little research attention in that country. SRH can be considered an indicator that mediates between the socioeconomic and health status of the population and use of HS, although consideration of other variables (chronic disease, disability, educational level, employment status, income level, or previous use of services) improves predictive capacity regarding HS use. For men, greater risk of HS use was explained by socioeconomic variables and chronic disease, whereas for women it was explained by health status, educational level, and previous use of services.

The interactions detected may reflect complex models. For men, poor SRH was predictive of HS use when combined with chronic disease, whereas for women it was predictive when combined with any educational level, but more intensely at the highest level.

This study suggests that in the current context of economic instability, efforts must be made to maintain social and health policies and employment protection because these exert a positive influence on the health of the population and on use of health services. It is necessary to monitor the self-rated health and socioeconomic and health status of the population.

Given the paucity of studies in Spain that have assessed the predictive capacity of SRH for HS use, and given recent socioeconomic changes, further research is necessary on this subject.

\section{Abbreviations}

Cl: Confidence interval; HS: Hospital services; MBDS: Minimum basic hospital data set; OR: Odds ratio; RV: Region of Valencia; RVHS2005: Region of Valencia Health Survey 2005; SRH: Self-rated health.

\section{Competing interests}

The authors declare that they have no competing interests.

\section{Authors' contributions}

NTF and AN were responsible for the study design and supervision of each research phase. NTF was involved in writing the manuscript and analysis and interpretation of the data. AN and JQ performed the statistical analysis. PPZ, $I M$, and JM contributed to the drafts of this manuscript. JC and CB were involved in acquisition and linkage of data. All authors read and approved the final version of the manuscript.

\section{Acknowledgements}

This research forms part of the doctoral dissertation of Nayara Tamayo-Fonseca at the University of Alicante, Spain.

We would like to thank Marc Nolasco Miñana for his help and assistance with the final translation of the text.

\section{Funding}

No financial support was received for this study.

\section{Author details}

'Department of Community Nursing, Research Unit for the Analysis of Mortality and Health Statistics, Preventive Medicine, Public Health and History of Science. University of Alicante. Campus de San Vicente del Raspeig s/n, Apartado 99, 03080 Alicante, Spain. ${ }^{2}$ Registro de Mortalidad de la Comunidad Valenciana, Servicio de Estudios Epidemiológicos y Estadísticas Sanitarias. Subdirección General de Epidemiología y Vigilancia de la Salud. Conselleria de Sanitat, Plaza de España 6, 03010 Alicante, Spain. ${ }^{3}$ Servicio de Análisis de Sistemas de Información Sanitaria, Conselleria de Sanitat, Generalitat Valenciana. C/Micer Mascó, 31-33, 46010 Valencia, Spain. ${ }^{4}$ Servicio del Plan de Salud, Dirección General de Salud Pública. Conselleria de Sanitat, Generalitat Valenciana. Avda. Cataluña, 21, 46020 Valencia, Spain.

Received: 20 June 2015 Accepted: 30 October 2015

Published online: 04 November 2015

\section{References}

1. Idler EL, Benyamini Y. Self-rated health and mortality: a review of twenty-seven community studies. J Health Soc Behav. 1997;38:21-37.

2. Benyamini Y, Idler EL. Community Studies Reporting Association between Self-Rated Health and Mortality: Additional Studies, 1995 to 1998. Res Aging. 1999;21:392-401.

3. DeSalvo K, Fan V, McDonell M, Fihn S. Predicting mortality and healthcare utilization with a single question. Health Serv Res. 2005;40:1234-46.

4. Jylhä M. What is self-rated health and why does it predict mortality? Towards a unified conceptual model. Soc Sci Med. 2009:69:307-16.

5. Bailis D, Segall A, Chipperfield J. Two views of self-rated general health status. Soc Sci Med. 2003;56:203-17.

6. Lang T, Delpierre C. How are you?: what do you mean? Eur J Public Health. 2009:19:353.

7. Schnittker J, Bacak V. The increasing predictive validity of self-rated health. PLoS One. 2014;9:e84933. doi:10.1371/journal.pone.0084933.

8. Weinberger M, Darnell J, Tierney W, Martz B, Hiner S, Barker J, et al. Self-rated health as a predictor of hospital admission and nursing home placement in elderly public housing tenants. Am J Public Health. 1986;76:457-9.

9. Milunpalo S, Vuori I, Oja P, Pasanen M, Urponen H. Self-rated health status as a health measure: The predictive value of self-reported health status on the use of physician services and on mortality in the working-age population. J Clin Epidemiol. 1997;50:517-28.

10. Bierman A, Bubolz T, Fisher E, Wasson J. How well does a single question about health predict the financial health of Medicare managed care plans? Eff Clin Pract. 1999;2:56-62.

11. McGee D, Liao Y, Cao G, Cooper R. Self-reported health status and mortality in a multiethnic US cohort. Am J Epidemiol. 1999;149:41-6.

12. DeSalvo K, Jones T, Peabody J, McDonald J, Finn S, Fan V, et al. Health care expenditure prediction with a single item, self-rated health measure. Med Care. 2009;47:440-7.

13. Sanderson D, Norlev J, Iburg K, Gispert R, Rasmussen NK. Perceived health. In: Robine JM, Jagger C, Romieu I, editors. Selection of a Coherent Set of Health Indicators for the European Union. Final Report. Montpellier: Euro-REVES; 2002. p. 81-96.

14. Rodríguez-Sanz M, Carrillo P, Borrell C. Desigualdades sociales en la salud, los estilos de vida y la utilización de los servicios sanitarios en las Comunidades Autónomas 1993-2003. Madrid: Ministerio de Sanidad y Consumo; 2006.

15. Pérez A, García F, Martín E, Romero L, Rodríguez M, Echevarría I, et al. Factores de riesgo de ingreso hospitalario en mayores de 64 años. Gac Sanit. 2000;14:363-70.

16. Suárez García F, Oterino D, Peiró S, Librero J, Barrero C, Parras N, et al. Factores asociados con el uso y adecuación de la hospitalización en personas mayores de 64 años. Rev Esp Salud Publica. 2001;75:237-48.

17. Suárez GF. Influencia del estado de salud en la mortalidad y hospitalización en una población de mayores de 64 años. Estudio poblacional: Universidad de Oviedo; 2006.

18. Tamayo-Fonseca N, Quesada JA, Nolasco A, Melchor I, Moncho J, Pereyra-Zamora P, et al. Self-rated health and mortality: A follow-up study of a Spanish population. Public Health. 2013;127:1097-104.

19. Sanfélix-Gimeno G, Ferreros I, Librero J, Peiró S. Caracterización de la suplementación de folatos en el embarazo a partir de la combinación de sistemas de información sanitaria. Gac Sanit. 2012;26:512-8.

20. Oficina del Plan de Salud. Encuesta de Salud de La Comunidad Valenciana 2005. Valencia: Conselleria de Sanitat. Generalitat Valenciana; 2007. 
21. Ministerio de Sanidad y Consumo. Metodología de análisis de la hospitalización en el Sistema Nacional de Salud. Modelo de indicadores basado en el Registro de Altas (CMBD). Madrid: Agencia de Calidad del Sistema Nacional de Salud; 2007.

22. Calle J, Saturno P, Parra P, Rodenas J, Pérez M, Eustaquio F, et al. Quality of the information contained in the minimum basic data set: Results from an evaluation in eight hospitals. Eur J Epidemiol. 2000;16:1073-80.

23. Barba R, Emilio Losa J, Guijarro C, Zapatero A. Fiabilidad del conjunto mínimo básico de datos (CMBD) en el diagnóstico de la enfermedad tromboembólica. Med Clin (Barc). 2006;127:255-7.

24. Yetano J, Laraudogoitia E. Documentación clínica. Aspectos legales y fuente de información para las bases de datos hospitalarias. Rev Española Cardiol Supl. 2007;7:2C-11C.

25. del Plan de Salud O. Encuesta de Salud de La Comunitat Valenciana 2010. Valencia: Conselleria de Sanitat. Generalitat Valenciana; 2012.

26. Ministerio de Sanidad Servicios Sociales e lgualdad. Encuesta Nacional de Salud de España 2011/12. Módulo sobre utilización de servicios sanitarios In: Portal estadístico del Sistema Nacional de Salud. http://mww.msssi.gob.es/estadEstudios/ estadisticas/encuestaNacional/encuestaNac2011/encuestaResDetall2011.htm. Accessed 17 jun, 2015.

27. Subdirección General de Información Sanitaria e Innovación. Los sistemas sanitarios en los países de la UE: Características e indicadores de salud 2013. Madrid: Ministerio de Sanidad, Servicios Sociales e Igualdad; 2014. http:// www.msssi.gob.es/estadEstudios/estadisticas/docs/Sist.Salud.UE_2013.pdf. Accessed 17 jun, 2015.

28. Moreno-Millán E, Molina-Morales A, Amate-Fortes I. Hospital utilization and aging in Spain (2006). Curr Aging Sci. 2010;3:151-7.

29. De Boer A, Wijker W, de Haes H. Predictors of health care utilization in the chronically ill: a review of the literature. Health Policy (New York). 1997;42:101-15.

30. Redondo-Sendino A, Guallar-Castillón P, Banegas JR, Rodríguez-Artalejo F. Gender differences in the utilization of health-care services among the older adult population of Spain. BMC Public Health. 2006;6:155.

31. Urbanos-Garrido R. Determinantes de salud y utilización de servicios sanitarios: un análisis de desigualdad desde la perspectiva de género. Presup y Gasto Público. 2011;64:117-30.

32. Instituto de Información Sanitaria. La hospitalización en el Sistema Nacional de Salud CMBD - Registro de Altas. Informe resumen 2010. Madrid: Ministerio de Sanidad, Servicios Sociales e lgualdad; 2012. http://www.msssi.gob.es/ estadEstudios/estadisticas/docs/Hospitalizacion_SNS_CMBD_Informe2010.pdf Accessed 17 jun, 2015.

33. Carrasco-Garrido P. Gil De Miguel A, Hernández V, Jiménez-García R. Health profiles, lifestyles and use of health resources by the immigrant population resident in Spain. Eur J Public Health. 2007;17:503-7.

34. Hernández-Quevedo C, Jiménez-Rubio D. A comparison of the health status and health care utilization patterns between foreigners and the national population in Spain: New evidence from the Spanish National Health Survey. Soc Sci Med. 2009;69:370-8.

35. Hernando L, Palomar J, Márquez M, Monteagudo O. Impacto de la inmigración sobre la asistencia hospitalaria: frecuentación, casuística y repercusión económica. Gac Sanit. 2009;23:208-15.

36. López A, Ramos J. Utilización de servicios sanitarios por parte de las poblaciones inmigrante y nativa en la Comunidad Autónoma de la Región de Murcia. Gac Sanit. 2009;23 Suppl 1:12-8.

37. Llop-Gironés A, Lorenzo I, Garcia-Subirats I, Aller M, Vázquez M. Acceso a los servicios de salud de la población inmigrante en España. Rev Esp Salud Publica. 2014;88:715-34.

38. Moncho J, Pereyra-Zamora P, Nolasco A, Tamayo-Fonseca N, Melchor I, Macia L. Trends and disparities in mortality among Spanish-born and Foreign-born populations residing in Spain, 1999-2008. J Immigr Minor Health. 2015;17:1374-84.

39. Urbanos-Garrido R. Explaining inequality in the use of Public Health Care Services: Evidence from Spain. Health Care Manag Sci. 2001;4:143-57.

40. Lostao L, Blane D, Gimeno D, Netuveli G, Regidor E. Socioeconomic patterns in use of private and public health services in Spain and Britain: implications for equity in health care. Health Place. 2014;25:19-25.

41. Garrido-Cumbrera M, Borrell C, Palencia L, Espelt A, Rodríguez-Sanz M, Pasarín M, et al. Social class inequalities in the utilization of health care and preventive services in Spain, a country with a National Health System. Int J Heal Serv. 2010;40:525-42.

42. Devaux M. Income-related inequalities and inequities in health care services utilisation in 18 selected OECD countries. Eur J Heal Econ. 2015;16:1-13.
43. Regidor E, Martínez D, Astasio P, Ortega P, Domínguez V, Calle M. Asociación de los ingresos económicos con la utilización y la accesibilidad de los servicios sanitarios en España al inicio del siglo XXI. Gac Sanit. 2006;20:352-9.

44. Farkas J, Kosnik M, Flezar M, Suskovic S, Lainscak M. Self-rated health predicts acute exacerbations and hospitalizations in patients with COPD. Chest. 2010;138:323-30.

45. Moreno X, Huerta M, Albala C. Autopercepción de salud general y mortalidad en adultos mayores. Gac Sanit. 2013;28:246-52.

46. Palència L, Espelt A, Rodríguez-Sanz M, Rocha K, Pasarín M, Borrell C. Trends in social class inequalities in the use of health care services within the Spanish National Health System, 1993-2006. Eur J Heal Econ. 2011;14:211-9.

47. Federación de Asociaciones para la Defensa de la Sanidad Pública. Doce propuestas para garantizar la sostenibilidad del Sistema Sanitario Público. Salud 2000. 2011;130:5-11.

48. Federación de Asociaciones para la Defensa de la Sanidad Pública. Informe sobre los recortes sanitarios en las Comunidades Autónomas. Salud 2000. 2012;136:11-5.

49. OECD. Health at a Glance: Europe 2012. OECD Publishing; 2012.

50. Librero J, Peiró S, Ordiñana R. Chronic Comorbidity and Outcomes of Hospital Care: Length of Stay, Mortality, and Readmission at 30 and 365 Days. J Clin Epidemiol. 1999;52:171-9.

\section{Submit your next manuscript to BioMed Central and take full advantage of:}

- Convenient online submission

- Thorough peer review

- No space constraints or color figure charges

- Immediate publication on acceptance

- Inclusion in PubMed, CAS, Scopus and Google Scholar

- Research which is freely available for redistribution 